\title{
OBSTRUCTIVE SLEEP APNEA RISK FOR DRIVING LICENSE APPLICANTS IN INDIA - A COMMUNITY BASED STUDY
}

\author{
ABHISHEK DUBEY ${ }^{1}$, DARSHAN K. BAJAJ ${ }^{1}$, APURVA MISHRA², BALENDRA PRATAP SINGH ${ }^{3}$, \\ VINAY GUPTA ${ }^{4}$, SURYA KANT $^{1}$, and SWATI DIXIT ${ }^{5}$ \\ ${ }^{1}$ King George's Medical University, Lucknow, India \\ Respiratory Medicine \\ ${ }^{2}$ King George's Medical University, Lucknow, India \\ Paediatric and Preventive Dentistry \\ ${ }^{3}$ King George's Medical University, Lucknow, India \\ Prosthodontics \\ ${ }^{4}$ King George's Medical University, Lucknow, India \\ Community Dentistry \\ ${ }^{5}$ Community Empowerment Lab, Lucknow, India \\ Nutrition
}

\begin{abstract}
Objectives: To determine the risk of obstructive sleep apnea (OSA) for male permanent driving license (DL) applicants of Lucknow, India. Material and Methods: In this cross-sectional community based, study body mass index, waist-hip ratio, blood pressure of each subject were determined as an anthropometric parameter along with the history of habit of smoking, tobacco chewing, alcohol consumption. STOP-Bang (Snoring, Tired or sleepy, Observed apnea, high blood Pressure, Body mass index, Age, Neck, Gender) Questionnaire - a scoring risk assessment tool - was applied for assessment of OSA risk (high OSA risk defined by score $\geq 3$ ) for 542 male DL recipients at 2 Regional Transport Office (RTO) centers in Lucknow, India. The statistical software SPSS 17.0 was applied to the testing. Results: In total $23 \%(\mathrm{~N}=125)$ of participants were found with the risk of OSA. High blood pressure $(\geq 140 / 90 \mathrm{~mm} \mathrm{Hg})$ was found for the maximum number of participants (40.5\%) followed by neck circumference $>40 \mathrm{~cm}$ (17.1\%), age (> 50 years old) (15.3\%), snoring (12.3\%) and tired/sleepy $(10.5 \%)$. Mean values of age, anthropometric measurements and blood pressure were observed significantly higher $(\mathrm{p}<0.001$ ) for participants with the OSA risk. In this population the risk of OSA risk (STOP-Bang score $\geq 3$ ) was observed for $6.7 \%$ of young ( $<35$ years old), $34 \%$ of middle ( $35-45$ years old) and $73 \%$ of elder age adults ( $>45$ years old). Conclusions: In view of findings of this study a high number of male driving license applicants were observed with the risk of OSA. Therefore efforts should be made to develop a national screening guideline/protocol for the OSA risk assessment for driving license applicants in India. This may reduce the possibility of road traffic accidents due to the OSA-associated fatigue and drowsiness behind the wheels. Int J Occup Med Environ Health 2018;31(1):25-36
\end{abstract}

Key words:

Obstructive sleep apnea, Drivers, Sleepiness, Road traffic accidents, STOP-Bang, High blood pressure

Received: May 25, 2016. Accepted: October 10, 2016.

Corresponding author: A. Dubey, King George's Medical University, Respiratory Medicine, Shahmina Road, Chowk, Lucknow, Uttar Pradesh 226003, India (email: writeuva@rediffmail.com). 


\section{INTRODUCTION}

Excessive daytime sleepiness (EDS) and road traffic accidents (RTA) have proven to be associated with obstructive sleep apnea (OSA). Globally, many national and regional guidelines clearly state that truckers and drivers should be carefully screened for OSA before granting or renewing a driving license (DL). Worldwide, nearly 1.3 million individuals lost their lives due to RTA every year. More than 50 million persons are wounded and countless remain paralyzed for their whole lives. The economic cost burden of RTA in developing nations is more than 100 billion dollars per year. Unfortunately $90 \%$ of casualties from these deaths also take place in these poor countries. In India, the number of RTA increased by $2.5 \%$ from 489400 in 2014 to 501423 in 2015. The total number of persons killed in RTA also increased by 4.6\% from 139671 in 2014 to 146133 in 2015 [1,2].

A detailed report of the road transport and highways ministry of India shows the driver's error (77.5\%) as one of the main causes culpable for RTA [3]. Statistics of previous reports also illustrate that $1 / 5$ of road RTA and nearly $25 \%$ of lethal and severe accidents are attributable to reduced alertness level of the drives. Moreover, a mishap associated with drowsiness of drivers is graver than other RTA, as drowsy drivers frequently don't make accurate response before the accident [4]. Several studies have revealed that, in comparison to normal persons, persons with OSA have an elevated risk of falling asleep while driving and are more likely to cause accidents [3,5-11]. Although the Indian Initiative on Obstructive Sleep Apnea guidelines ("INOSA Guidelines 2014") clearly state that individuals with a history of EDS, habitual snoring, obesity, hypertension (HT) RTA and other persons with high risk should go through a complete clinical assessment [12]. Two Indian cross-sectional community studies using a sleep questionnaire and polysomnography (PSG) estimated OSA prevalence between 9.3\% (13.5\% for males) and $13.7 \%$ (19.7\% for males), respectively $[13,14]$.
In these studies, age, male sex, obesity and central obesity (waist-hip ratio) were observed as significant risk factors for OSA occurrence in Indian population [13,14]. In this manner every 5 th or 6 th Indian male appeared in the risk of OSA and associated hazards of drowsy driving, but screening for OSA in DL applicants is neither mentioned specifically in the declaration of physical fitness documents nor in the medical fitness certificate, documented and provided by the state government authorized clinician [15]. Thus this study was performed to estimate the risk of OSA and associated risk factors for male recipients of permanent DL in Lucknow, India.

\section{MATERIAL AND METHODS}

The sample size $(\mathrm{N})$ was calculated using the formula:

$$
\mathrm{N}=\frac{\mathrm{Z}^{2} \times \mathrm{P}(1-\mathrm{P})}{\mathrm{d}^{2}}
$$

where:

$\mathrm{Z}-\mathrm{Z}$ statics for the $95 \%$ level of confidence,

$\mathrm{P}$ - expected prevalence,

$\mathrm{d}$ - desired precision.

We expected $9 \%$ prevalence (so $p=0.09$ ) as a previous study on Indian male population [14]. We calculated the sample size of the study setting 95\% level of confidence. Considering approximate loss of $20 \%$ of participants, 599 male DL applicants presented to give fingerprints as a final stage to get a permanent DL at the Assistant Regional Transport Office (ARTO) offices Lucknow (in the last week of March 2015 at center 1 and 3rd week of June 2015 at center 2) were approached and 542 participants were finally recruited in the study (Figure 1). Demographic information, history of habit of tobacco chewing, smoking, alcohol consumption and information on STOP-Bang (Snoring, Tired or sleepy, Observed apnea, high blood pressure, Body mass index, Age, Neck, Gender) Questionnaire were collected [16]. Body mass 


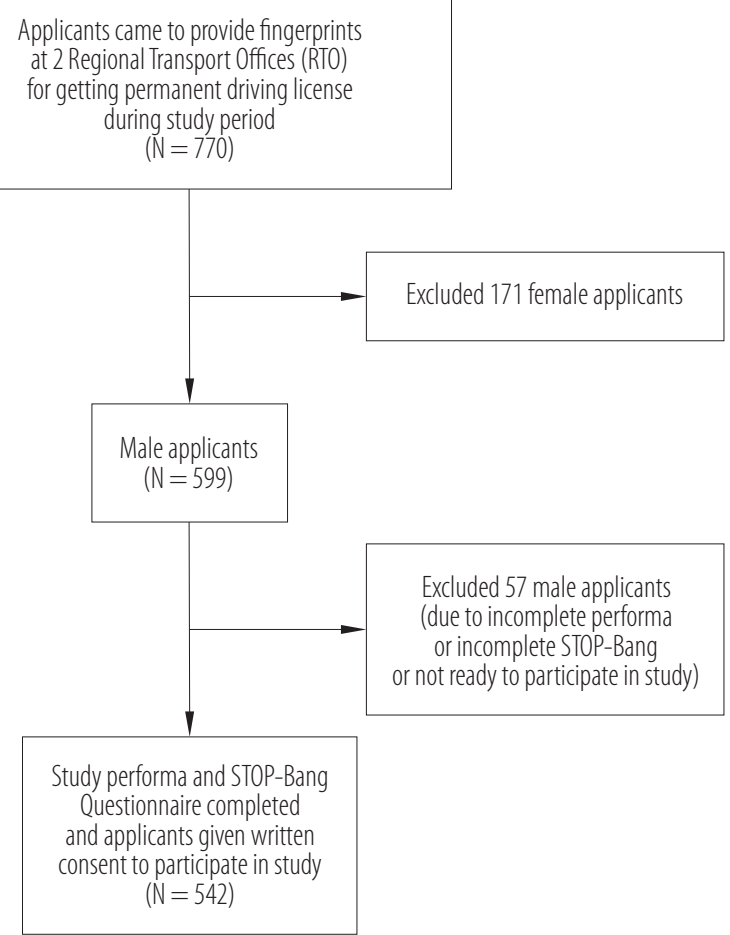

STOP-Bang - Snoring, Tired or sleepy, Observed apnea, high blood Pressure, Body mass index, Age, Neck, Gender.

Fig. 1. Stages in participant recruitment to study of obstructive sleep apnea (OSA) risk for male permanent driving license applicants of Lucknow, India

index (BMI) cutoffs according to STOP-Bang, the World Health Organization (WHO) expert consultation group and specific Indian recommendations were selected for the analysis purposes [16-18].

Body mass index was calculated by dividing weight (in $\mathrm{kg}$ ) by the height (in $\mathrm{m}^{2}$ ). The weight of the DL applicants was precisely calculated close to $0.5 \mathrm{~kg}$ with the light clothing and after removing shoes, by means of a standard weight scale. Height was calculated close to a centimeter $(\mathrm{cm})$ with stadiometer.

Waist circumference (WC) was assessed by a measuring tape in $\mathrm{cm}$. Waist circumference was calculated at minimal inspiration amid the edge of the lowest ribs and iliac crest, hip circumference (HC) was calculated at the highest circumference level on the hips by a measuring tape. Neck circumference (NC) was also assessed by a measuring tape at cricothyroid membrane level. Waist-hip ratio (WHR) was calculated by dividing WC from HC.

Blood pressure (BP) was calculated after 10 min relaxation of subjects at screening time. Blood pressure reading was taken with sphygmomanometer device. If this reading did not show HT, then it was accepted, if it did signify HT, then a second evaluation was made and mean of these findings were reported for the use of the study. High BP was defined as blood pressure $\geq 140 \mathrm{~mm} \mathrm{Hg}$ systolic and or diastolic blood pressure $\geq 90 \mathrm{~mm} \mathrm{Hg}$, or a known hypertensive on medication.

Hindi translated version of the STOP-Bang Questionnaire tool was applied to the study. This tool included yes or no queries: " $S$ " indicates the presence for loud snoring, " $\mathrm{T}$ " indicates the existence of tiredness, fatigue, or EDS, "O" indicates observed breathing pause during sleep, and "P" indicates occurrence of high BP. Each affirmative response results in one point.

The "BANG" component of the tool is about BMI, age, $\mathrm{NC}$ and gender of the subjects. Blood pressure, BMI, age and $\mathrm{NC}$ of the subjects were assessed by a trained paramedic technician. Subjects got an extra point for their STOP-Bang scoring for the presence of other clinical characteristics, i.e., BMI greater than $35 \mathrm{~kg} / \mathrm{m}^{2}$, age more than 50 years old, an $\mathrm{NC}$ more than $40 \mathrm{~cm}$, and male sex. Subjects were acknowledged as possessing a high risk for OSA if they are shown STOP-Bang score equal or greater than 3 . The maximum possible score is 8 . Ethical approval was taken from the institutional ethics committee (IEC) and the research was performed in compliance with the principles in the Declaration of Helsinki.

\section{Statistical analysis}

Mean and standard deviation (SD) were calculated for the continuous parameters and frequency division and percentage for the categorical parameters. The Student's t-test was applied to calculate the significance for the continuous 
parameters. Pearson correlation analysis was applied to calculate correlation between various variables. The $p$ value of $<0.05$ was considered as statistically significant. The statistical software SPSS 17.0 was applied in the testing.

\section{RESULTS}

The highest number of participants in the study belonged to 20-29 year of age group (Table 1). Mean age, BMI and $\mathrm{NC}$ of all studied participants $(\mathrm{N}=542)$ were found to be 31.8 years old, $24 \mathrm{~kg} / \mathrm{m}^{2}$ and $36.7 \mathrm{~cm}$, respectively (Table 1). High BP was observed in $40.5 \%$ of the studied participants, tobacco chewing in $10.7 \%$, smoking in $9.4 \%$ and alcohol consumption habit in $3.5 \%$ participants (Table 1). In response to the STOP-Bang Questionnaire maximum positive response $(40.5 \%)$ of participants was found for high BP (greater or equal to $140 / 90 \mathrm{~mm} \mathrm{Hg}$ ) followed by $\mathrm{NC}>40 \mathrm{~cm}(17.1 \%)$, age $>50$ years old $(15.3 \%)$, snoring (12.3\%) and tired/sleepy (10.5\%), respectively

Table 1. Demographic characteristics of study participants - male permanent driving license applicants, Lucknow, India

\begin{tabular}{|c|c|c|c|}
\hline \multirow[b]{2}{*}{ Parameter } & \multicolumn{3}{|c|}{ Respondents } \\
\hline & $\begin{array}{c}\text { total } \\
(\mathrm{N}=542)\end{array}$ & $\begin{array}{l}\text { RTO center } 1 \\
(\mathrm{~N}=313)\end{array}$ & $\begin{array}{c}\text { RTO center } 2 \\
(\mathrm{~N}=229)\end{array}$ \\
\hline 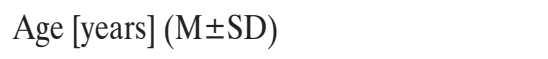 & $31.80 \pm 13.20$ & $32.60 \pm 13.80$ & $30.70 \pm 12.20$ \\
\hline Body mass index $(\mathrm{BMI})\left[\mathrm{kg} / \mathrm{m}^{2}\right](\mathrm{M} \pm \mathrm{SD})$ & $24.00 \pm 4.30$ & $23.80 \pm 4.10$ & $24.20 \pm 4.60$ \\
\hline \multicolumn{4}{|l|}{ Circumference $[\mathrm{cm}](\mathrm{M} \pm \mathrm{SD})$} \\
\hline neck & $36.70 \pm 3.10$ & $36.90 \pm 3.00$ & $36.40 \pm 3.20$ \\
\hline waist & $88.00 \pm 13.00$ & $88.20 \pm 12.50$ & $87.60 \pm 13.60$ \\
\hline hip & $94.00 \pm 8.20$ & $94.10 \pm 7.80$ & $93.90 \pm 8.70$ \\
\hline Waist-hip ratio & $0.93 \pm 0.08$ & $0.93 \pm 0.08$ & $0.92 \pm 0.08$ \\
\hline \multicolumn{4}{|l|}{ Blood pressure $[\mathrm{mm} \mathrm{Hg}](\mathrm{M} \pm \mathrm{SD})$} \\
\hline systolic & $129.20 \pm 18.20$ & $133.00 \pm 17.60$ & $124.00 \pm 17.70$ \\
\hline diastolic & $83.90 \pm 10.90$ & $86.70 \pm 9.70$ & $80.00 \pm 11.30$ \\
\hline Mallampati grade (1-4) & $2.90 \pm 1.00$ & $3.40 \pm 0.70$ & $2.30 \pm 1.00$ \\
\hline \multicolumn{4}{|l|}{ Existing conditions $[\mathrm{n}(\%)]$} \\
\hline high blood pressure & $220(40.5)$ & $150(47.9)$ & $70(30.5)$ \\
\hline tobacco chewer & $58(10.7)$ & $34(10.8)$ & $24(10.4)$ \\
\hline smoker & $51(9.4)$ & $22(7.0)$ & $29(12.6)$ \\
\hline alcohol consumption & $19(3.5)$ & $12(3.8)$ & $7(3.0)$ \\
\hline \multicolumn{4}{|l|}{ Age $[\mathrm{n}(\%)]$} \\
\hline$<20$ years & $92(17.0)$ & $58(18.5)$ & $34(14.8)$ \\
\hline $20-29$ years & $201(37.0)$ & $102(32.6)$ & 99 (43.2) \\
\hline $30-39$ years & $112(20.6)$ & $61(19.5)$ & $51(22.2)$ \\
\hline 40-49 years & $54(10.0)$ & $38(12.1)$ & $16(6.9)$ \\
\hline$\geq 50$ years & $83(15.3)$ & $54(17.2)$ & 29 (12.6) \\
\hline
\end{tabular}

M - mean; SD - standard deviation.

RTO - Regional Transport Office. 
Table 2. Positive responses to STOP-Bang Questionnaire from study participants - male permanent driving license applicants, Lucknow, India

\begin{tabular}{lccc}
\hline \multirow{2}{*}{\multicolumn{1}{c}{ Positive responses }} & \multicolumn{2}{c}{ Respondents } \\
& & {$[\mathrm{n}(\%)]$} & \\
\cline { 2 - 4 } & & RTO centre 1 \\
$(\mathrm{N}=313)$ & $\begin{array}{c}\text { RTO centre 2 } \\
(\mathrm{N}=229)\end{array}$ \\
\hline Snoring & $67(12.3)$ & $33(10.5)$ & $34(14.8)$ \\
Tired/sleepy & $57(10.5)$ & $33(10.5)$ & $24(10.4)$ \\
Observed apnea & $24(4.4)$ & $12(3.8)$ & $12(5.2)$ \\
High blood pressure $(\geq 140 / 90 \mathrm{~mm} \mathrm{Hg})$ & $220(40.5)$ & $150(47.9)$ & $70(30.5)$ \\
Body mass index $(\mathrm{BMI})$ & $11(2.0)$ & $5(1.5)$ & $6(2.6)$ \\
Age $>$ 50 years old & $83(15.3)$ & $54(17.2)$ & $29(12.6)$ \\
Neck circumference $>40 \mathrm{~cm}$ & $93(17.1)$ & $58(18.5)$ & $35(15.2)$ \\
Gender & $542(100.0)$ & $313(100.0)$ & $229(100.0)$ \\
STOP-Bang Questionnaire score $\geq 3$ & $125(23.0)$ & $77(24.6)$ & $48(20.9)$ \\
\hline
\end{tabular}

STOP-Bang - Snoring, Tired or sleepy, Observed apnea, high blood Pressure, Body mass index, Age, Neck, Gender.

RTO - Regional Transport Office.

(Table 2). By applying the STOP-Bang scoring risk assessment tool (the high risk of OSA defined by having STOPBang score $\geq 3,23 \%(\mathrm{~N}=125)$ participants were found with high risk of OSA for the studied population. The high risk of OSA (STOP-Bang score $\geq 3$ ) was observed slightly higher at RTO center $1(24.6 \%)$ in comparison to RTO center $2(20.9 \%)$ (Table 2).

The independent unpaired t-test was applied to compare mean values of various parameters (age, weight, height, BMI, systolic and diastolic BP, NC, WC and WHR) of participants with and without high risk of OSA. Mean values of all parameters were observed significantly higher $(\mathrm{p}<0.001)$ in participants with high risk of OSA, except for height variable $(\mathrm{p}=0.307)$ (Table 3$)$.

Participants were also compared on the basis of 3 broad age group classes (young adults, middle age adults and elder age adults) defined/classified as < 35 years old, 35-45 years old and $>45$ years old, respectively (Table 4 ). Young adults were comprised in the largest number $(66.2 \%)$ followed by elder age $(17.9 \%)$ and middle age

Table 3. Summary statistics of study participants - male permanent driving license applicants - with high risk of obstructive sleep apnea (OSA) and without high risk of OSA, Lucknow, India

\begin{tabular}{lccr}
\hline & \multicolumn{2}{c}{$\begin{array}{c}\text { Respondents } \\
\text { Variable }\end{array}$} & \multirow{2}{c}{$\mathrm{p}=542)$} \\
\cline { 2 - 3 } & $\begin{array}{c}\text { without OSA high risk } \\
(\mathrm{N}=417)\end{array}$ & $\begin{array}{c}\text { with OSA high risk } \\
(\mathrm{N}=125)\end{array}$ & \\
\hline Age [years] $(\mathrm{M} \pm \mathrm{SD})$ & $27.30 \pm 9.60$ & $46.90 \pm 12.40$ & $<0.001$ \\
Height $[\mathrm{cm}](\mathrm{M} \pm \mathrm{SD})$ & $167.40 \pm 7.09$ & $167.10 \pm 6.60$ & 0.307 \\
Weight $[\mathrm{kg}](\mathrm{M} \pm \mathrm{SD})$ & $63.80 \pm 10.50$ & $78.60 \pm 13.50$ & $<0.001$ \\
Body mass index $(\mathrm{BMI})\left[\mathrm{kg} / \mathrm{m}^{2}\right](\mathrm{M} \pm \mathrm{SD})$ & $22.70 \pm 3.50$ & $28.10 \pm 4.30$ & $<0.001$ \\
\hline
\end{tabular}


Table 3. Summary statistics of study participants - male permanent driving license applicants - with high risk of obstructive sleep apnea (OSA) and without high risk of OSA, Lucknow, India - cont.

\begin{tabular}{lccc}
\hline & \multicolumn{2}{c}{$\begin{array}{c}\text { Respondents } \\
\text { Variable }\end{array}$} & \multirow{2}{c}{$\mathrm{p}$} \\
\cline { 2 - 3 } & $\begin{array}{c}\text { without OSA high risk } \\
(\mathrm{N}=417)\end{array}$ & $\begin{array}{c}\text { with OSA high risk } \\
(\mathrm{N}=125)\end{array}$ & \\
\hline Blood pressure $[\mathrm{mm} \mathrm{Hg}](\mathrm{M} \pm \mathrm{SD})$ & & & \\
$\quad$ systolic & $125.20 \pm 15.50$ & $142.50 \pm 20.30$ & $<0.001$ \\
$\quad$ diastolic & $82.40 \pm 10.80$ & $89.00 \pm 9.90$ & $<0.001$ \\
Circumference $[\mathrm{cm}](\mathrm{M} \pm \mathrm{SD})$ & & & \\
$\quad$ neck & $35.70 \pm 2.40$ & $40.10 \pm 2.80$ & $<0.001$ \\
$\quad$ Waist & $84.00 \pm 10.70$ & $101.30 \pm 11.00$ & $<0.001$ \\
Waist-hip ratio $(\mathrm{M} \pm \mathrm{SD})$ & $0.91 \pm 0.07$ & $1.00 \pm 0.07$ & $<0.001$ \\
Mallampati grade $(1-4)(\mathrm{M} \pm \mathrm{SD})$ & $2.80 \pm 1.00$ & $3.30 \pm 0.80$ & $<0.001$ \\
STOP-Bang Questionnaire score $(\mathrm{M} \pm \mathrm{SD})$ & $1.40 \pm 0.40$ & $4.00 \pm 1.20$ & $<0.001$ \\
\hline
\end{tabular}

STOP-Bang - Snoring, Tired or sleepy, Observed apnea, high blood Pressure, Body mass index, Age, Neck, Gender.

Table 4. Age based classification wise summary statistics of study participants - male permanent driving license applicants, Lucknow, India

\begin{tabular}{|c|c|c|c|}
\hline \multirow{2}{*}{ Variable } & \multicolumn{3}{|c|}{$\begin{array}{c}\text { Respondents } \\
(\mathrm{N}=542) \\
{[\mathrm{n}(\%)]}\end{array}$} \\
\hline & $\begin{array}{c}\text { young adults } \\
(<35 \text { years old }) \\
(\mathrm{N}=359,66.2 \%)\end{array}$ & $\begin{array}{l}\text { middle age adults } \\
(35-45 \text { years old) } \\
(\mathrm{N}=86,15.9 \%)\end{array}$ & $\begin{array}{l}\text { elder age adults } \\
(>45 \text { years old }) \\
(\mathrm{N}=97,17.9 \%)\end{array}$ \\
\hline Snoring & $19(5.3)$ & $22(25.5)$ & $26(26.8)$ \\
\hline Tired/Sleepy & $6(1.7)$ & $15(17.4)$ & $36(37.1)$ \\
\hline Observed apnea & $7(1.9)$ & $7(8.1)$ & $10(10.3)$ \\
\hline High blood pressure & $122(34.0)$ & $40(46.5)$ & $58(59.7)$ \\
\hline \multicolumn{4}{|l|}{ Body mass index (BMI) } \\
\hline$>35^{\mathrm{a}}\left[\mathrm{kg} / \mathrm{m}^{2}\right]$ & $1(0.3)$ & $6(6.9)$ & $4(4.1)$ \\
\hline$>30^{\mathrm{a}}\left[\mathrm{kg} / \mathrm{m}^{2}\right]$ & $23(6.4)$ & $11(12.7)$ & $13(13.4)$ \\
\hline$>27.5^{\mathrm{a}}\left[\mathrm{kg} / \mathrm{m}^{2}\right]$ & $37(10.3)$ & $25(29.0)$ & $35(36.0)$ \\
\hline$>25^{\mathrm{b}}\left[\mathrm{kg} / \mathrm{m}^{2}\right]$ & $91(25.3)$ & $53(61.6)$ & $61(62.8)$ \\
\hline$>23^{\mathrm{b}}\left[\mathrm{kg} / \mathrm{m}^{2}\right]$ & $172(47.9)$ & $68(79.0)$ & $77(79.3)$ \\
\hline \multicolumn{4}{|l|}{ Circumference } \\
\hline neck $>40 \mathrm{~cm}$ & $16(4.4)$ & $21(24.4)$ & $31(31.9)$ \\
\hline waist $>90 \mathrm{~cm}$ & $90(25.0)$ & $62(72.0)$ & $75(77.0)$ \\
\hline STOP-Bang Questionnaire score $\geq 3$ & $24(6.7)$ & $30(34.0)$ & $71(73.0)$ \\
\hline
\end{tabular}

a WHO expert consultation specific obesity cutoff.

${ }^{\mathrm{b}}$ Overweight and obese as Asian Indians cutoff.

STOP-Bang - Snoring, Tired or sleepy, Observed apnea, high blood Pressure, Body mass index, Age, Neck, Gender. 
Table 5. Correlation between variables in study of obstructive sleep apnea (OSA) risk for male permanent driving license (DL) applicants, Lucknow, India

\begin{tabular}{|c|c|c|c|c|c|c|c|c|c|c|}
\hline \multirow{2}{*}{ Variable } & \multicolumn{10}{|c|}{ Pearson's correlation } \\
\hline & 1 & 2 & 3 & 4 & 5 & 6 & 7 & 8 & 9 & 10 \\
\hline 1. Snoring & 1 & & & & & & & & & \\
\hline 2. Tired & $0.419^{* *}$ & 1 & & & & & & & & \\
\hline 3. Observed apnea & $0.436^{* *}$ & $0.306^{* *}$ & 1 & & & & & & & \\
\hline 4. High blood pressure & $0.111^{*}$ & $0.157^{* *}$ & $0.114^{*}$ & 1 & & & & & & \\
\hline 5. Body mass index (BMI) & $0.263^{* *}$ & $0.163^{* *}$ & $0.605^{* *}$ & $0.120^{*}$ & 1 & & & & & \\
\hline 6. Neck circumference & $0.394^{* *}$ & $0.513^{* *}$ & $0.425^{* *}$ & $0.151^{* *}$ & $0.316^{* *}$ & 1 & & & & \\
\hline 7. Age cut & $0.213^{* *}$ & $0.422^{* *}$ & $0.157^{* *}$ & $0.191^{* *}$ & $0.084^{*}$ & $0.350^{* *}$ & 1 & & & \\
\hline 8. Tobacco chewing & $-0.039^{*}$ & $0.017^{*}$ & $-0.045^{*}$ & $0.005^{*}$ & $-0.007^{*}$ & $-0.094^{*}$ & $-0.064 *$ & 1 & & \\
\hline 9. Smoking & $0.040^{*}$ & $0.038^{*}$ & $0.040^{*}$ & $-0.023^{*}$ & $0.008^{*}$ & $0.036^{*}$ & $-0.005^{*}$ & $0.104^{*}$ & 1 & \\
\hline 10. Alcohol consumption & $0.080^{*}$ & $0.032^{*}$ & $0.007^{*}$ & $-0.096^{*}$ & $-0.027^{*}$ & $-0.060^{*}$ & $0.058^{*}$ & $0.063^{*}$ & $0.324 * *$ & 1 \\
\hline
\end{tabular}

$* \mathrm{p}<0.01 ; * * \mathrm{p}<0.001$.

adults (15.9\%) (Table 4). Snoring was prominently reported for middle and elder age adults, $25.5 \%$ and $26.8 \%$, respectively, while it was 5 times less reported phenomenon for young adults (5.3\%). Snoring, tiredness/EDS, observed apnea, high BP, BMI more than $35 \mathrm{~kg} / \mathrm{m}^{2}$, and $\mathrm{NC}>40 \mathrm{~cm}$, parameters were higher in the middle and elder age adults than young adults (Table 4). Obesity parameters (BMI, NC, WC) were mostly within the normal range for young adults while these parameters were found higher for middle and elder adults. STOP-Bang score $\geq 3$ was observed for $6.7 \%$ of young adults, $34 \%$ of middle age adults and $73 \%$ of elder age adults (Table 4 ). Snoring was observed as positively correlated with tiredness, observed apnea, high BP, age cut off (age $>50$ years old), smoking and alcohol consumption (Table 5).

\section{DISCUSSION}

This study was undertaken for male applicants, as the male gender is itself a risk factor for the occurrence of OSA and the prevalence of OSA in the Indian population is threefold higher for men as compared to women $[13,14]$. The prevalence of the high risk OSA observed rising (6.7\% of young adults, $34 \%$ of middle age adults and $73 \%$ of elder age adults) in the higher age group, which is in accordance with the findings of an earlier Indian community based study, concluding age as a risk factor for the occurrence of OSA [14].

Some other studies are in harmony with our study, which showed a 2-3-fold elevated occurrence of OSA for older persons $[19,20]$. It has been recommended that aging elevate fat deposition around the pharynx which is not dependent on either systemic fat mass or weakening of genioglossus negative pressure reflex is mostly the main cause of this inclination [19,21].

Similarly, for our subjects, obesity also seems to be age dependent phenomenon, as in the young adult age group only one applicant was having morbid obesity (BMI $>35 \mathrm{~kg} / \mathrm{m}^{2}$ ) while this level of obesity was present for $6.9 \%$ and $4.1 \%$ of middle and elder age adults, respectively. Obesity is one of the most important contributing causes for the occurrence and progression of OSA. In Wisconsin cohort, it was observed that persons originally not affected by OSA, a $10 \%$ enhance in body weight was observed to be linked to a 6-fold increased possibility of occurrence of OSA while 
on the other hand, $10 \%$ weight reduction results in a $26 \%$ decline in the apnea hypopnea index (AHI) [22].

Numerous theories have been hypothesized to describe how fat deposition raises the possibility of OSA. These involve fat deposition in the pharyngeal region of the airway resulting in its elevated chances of collapsibility. Central obesity (abdominal fat deposition) results in a decline in lung volume in addition to decrease in functional residual capacity. This leads to diminished caudal traction which results in a rise in the probability of pharyngeal collapsibility $[19,23,24]$.

Translated local language version (Hindi) of the STOPBang was used in this study as in distinction to other screening tools like the commonly used Berlin questionnaire, as it is smaller and more uncomplicated tool [25]. It comprises a subjective 4-point assessment (STOP) and a 4-point part about demographic assessments and other measurement (BANG) $[19,26]$. The STOP-Bang tool is considerably simpler to score than Berlin Questionnaire. Originally the STOP-Bang tool was applied to preoperative surgical patients for screening of OSA [16]. The STOPBang tool was observed precisely sensitive in $83.6 \%, 92.9 \%$, and $100 \%$ in mild, moderate and severe respectively in that population [27]. Researchers had retrospectively assessed the STOP-Bang tool in a sleep lab setting. They collected the corresponding responses of STOP from other questionnaires/tools, completed by patients, and adding together BANG part from clinical records. This study established the fact that the STOP-Bang tool had a sensitivity of $81.5 \%$ for accurate diagnosing OSA (AHI $\geq 5$ ) [28]. Obstructive sleep apnea risk observed in the male population in this study, is in accordance with previous Indian cross-sectional community studies $[12,13]$.

In our setting, high BP was found for $40.5 \%$ of participants, which is slightly higher than a recent study by Moser et al. [29] and another published systematic review/metaanalysis of Anchala et al. [30], on prevalence, awareness, and control of HT (Hypertension in India). These varia- tions in prevalence may perhaps also be linked to the white coat effect, machine applied for the BP measurement, demographic, genetic and anthropological makeup of the screened subjects.

Aging, smoking, alcohol consumption, tobacco chewing, obesity specifically central obesity, less intake of vegetables and fruits, high intake of dietary fat and salt, and sedentary lifestyle are the important risk factors for high BP in Indian population [30]. Urban population is more prone to these risk factors and thus having higher prevalence. Our study participants were residents of urban area so they may have an elevated occurrence of high BP. Our results are almost similar to a previous study done on male bus drivers of Corporation Bus stand Kozhikode, Kerala, India by Lakshman et al. in which $41.3 \%$ of participants had high BP [31]. Similar results were found in another very large community based screening program organized in 53 camps in 13 representative geographic locations in India, where prevalence of high BP was observed 43.5\% [32]. Our screening camp results match up to this and other studies from India and also from other Asian countries in showing comparatively high prevalence of high BP. Thus, this may be related to design (camp unit study) in differing to from the home to home screening method [32-35].

Tobacco chewing was observed for $10.8 \%$ of participants, smoking and alcohol consumption habits were found for $7.7 \%$ and $3.5 \%$ of the studied participants, respectively in our study setting. Smoking was found associated with elevated occurrence of OSA. Although this association is comparatively weaker, but smoking may affect and increase the cardiovascular risk linked with OSA [36-38]. In responses to the STOP-Bang Questionnaire, only $12.3 \%$ and $10.5 \%$ of participants positively responded for snoring and tiredness/sleepiness respectively, and just $4.4 \%$ of the total number of participants positively responded for observed apnea in this study. These symptoms score reporting and self-identification apparently appears poorly reported and or under recognized. In another study designed to find 
out the correlation between subjective against objective evaluation of OSA for commercial motor drivers acknowledged significantly higher incidences $(41 \%)$ of undetected OSA shown by a portable testing device, while just $12 \%$ of motor drivers stated symptoms of EDS [39].

If we review prior DL rules and health check-up features described by transport authorities in 25 countries in the European region, EDS was indicated in 9 countries, while OSA was reported in only 10 countries [40]. In these countries, a person with untreated OSA was strictly defined unfit for driving a motor vehicle. To get back the motor driving license, 7 countries depended on a medical doctor's health certificate supported by symptom management and acquiescence by prescribed treatment, while in 2 countries it was up to the applicants to make a judgement (on his physician's recommendation) of driving again. France is the only country in the European Union (EU) where a standardized electroencephalography (EEG) based maintenance of wakefulness test (MWT) was compelled for professional motor drivers with OSA risk. On the other hand, even rare health conditions (for example narcolepsy) are thought to be a motor driving safety threat more commonly than OSA [40].

New strict EU directives on driver licensing for patients with OSA were issued to be mandatory implemented by all member states from December 31, 2015 onwards [41]. According to these new directives, individuals with risk of OSA (moderate or severe) shall be referred for further health check-ups re-examinations before granting or renewing a motor driving license. Driving license may be permitted to those applicants who demonstrate satisfactory management of their disease, acquiescence with appropriate treatment and improvement in EDS and drowsiness, confirmed by authorized clinician. These individuals getting OSA treatment therapies shall be underwent to regular health check-ups, at regular intervals within 3 years for non-professional motor drivers and within one year for professional motor drivers, to determine treatment compliance [41].
The American Thoracic Society Clinical Practice Guideline to this domain clearly states that timely clinical detection, adequate treatment and tutoring of the patient and their relatives may reduce the incidence of drowsiness linked RTA in high-risk drivers with OSA [42]. This guideline recommends PSG or at-home portable monitoring for individuals with a high risk of OSA.

According to this guideline physicians should formulate a specific practice-oriented arrangement for updating and educating these persons and their relatives regarding hazards of sleepiness and tiredness during motor driving. Relatives should also be informed about the risk of EDS and life style modification therapies. Physicians and health workers should customarily screen suspected OSA cases about non-OSA reasons of EDS (sleep deprivation, sedatives or alcohol consumption) or any associated neurocognitive co-morbidity (depression) [42].

In Canada, the Canadian Sleep Society, Canadian Thoracic Society, and Sleep Disordered Breathing Clinical Assembly suggested that licensing authorities should think about the references presented by the expert medical practitioner [43]. The National OSA guidelines of India also advocate similarly, but its legal and regulatory framework, procedures are totally absent till date [12].

Ideally, regulatory bodies, legal system, clinicians and patient (drivers with OSA) should have a joint and reciprocal appreciative of the significance of acknowledgement of drowsiness and tiredness as a health hazard as well as a lethal threat for safe and sound motor driving. Society is responsible for making a decision for threshold for forbearance and execution of the regulations. Clinicians are accountable for the management of sleep disorders but are also citizens and opinion makers. Patients (drivers with OSA) are workers, family members and citizens. At any time anyone may be a victim of the ignorance of all or even fewer of us.

Road traffic accident injuries put an enormous load on our health structures [2]. Obstructive sleep apnea and EDS 
are major independent risk causes for RTA so it is very important that screening and awareness programs need to be prepared in coordination with local transport organizations, authorities and health agencies. Drivers should be systematically screened for OSA at the time of issuing or renewal of DL. This questionnaire based study on male applicants was carried out at 2 urban centers, so results need further validation through a multi-center study of both genders. Polysomnography and MWT may be included in further study.

\section{CONCLUSIONS}

This study evidently indicates a high number of Indian male driving license applicants with the risk of OSA. No specific objective or subjective screening procedure for OSA is done for the driving license applicants in India as compared to western countries. Thus subjects with the risk of OSA remain undiagnosed and unreported. This may raise the risk of traffic accident, posing an unwanted burden on health infrastructure and the growing economy of India.

Therefore, guidelines should be laid to develop a national screening protocol for the OSA risk assessment for driving license applicants in India. Clinicians should carefully evaluate DL applicants for OSA and suspected OSA cases should be referred for comprehensive evaluation and PSG. This will reduce the possibility of RTA due to OSA associated sleepiness, fatigue and drowsiness of the drivers.

\section{ACKNOWLEDGMENTS}

We are thankful to the officials and workers of the regional transport office, UP, Lucknow, India.

\section{REFERENCES}

1. Ministry of Road Transport and Highways [Internet]. New Delhi: The Ministry; 2017 [cited 2016 Aug 14]. Road accidents in India 2015. Available from: http://pibphoto.nic.in/ documents/rlink/2016/jun/p20166905.pdf.
2. FIA Foundation [Internet]. London: The Foundation; 2017 [cited 2015 Apr 14]. United Nations Decade of action for road safety 2011-2020. Available from: http://www.decadeofaction.org.

3. Gopalakrishnan S. A public health perspective of road traffic accidents. J Family Med Prim Care. 2012;1(2):144-50, https://doi.org/10.4103/2249-4863.104987.

4. Saradadevi M, Bajaj P. Driver fatigue detection using mouth and yawning analysis. Int J Comput Sci Netw Secur. 2008;8(6):183-8.

5. Tregear S, Reston J, Schoelles K, Phillips B. Obstructive sleep apnea and risk of motor vehicle crash: Systematic review and meta-analysis. J Clin Sleep Med. 2009;5(6):573-81.

6. Rodenstein D. Sleep apnea: Traffic and occupational accidents - Individual risks, socioeconomic and legal implications. Respiration. 2009;78(3):241-8, https://doi.org/10.11 59/000222811.

7. Amra B, Dorali R, Mortazavi S, Golshan M, Farajzadegan Z, Fietze I, et al. Sleep apnea symptoms and accident risk factors in Persian commercial vehicle drivers. Sleep Breath. 2012;16(1):187-91, https://doi.org/10.1007/s11325010-0473-x.

8. Horstmann S, Hess CW, Bassetti C, Gugger M, Mathis J. Sleepiness-related accidents in sleep apnea patients. Sleep. 2000;23(3):383-9, https://doi.org/10.1093/sleep/23.3.1e.

9. Irwin ED, Reicks P, Beal A, Byrnes M, Matticks C, Beilman G. A prospective study of the role of sleep related disordered breathing as a risk factor for motor vehicle crashes and the development of systemic complications in non-commercial drivers. World J Emerg Surg. 2014;9(1):2, https:// doi.org/10.1186/1749-7922-9-2.

10. De Mello MT, Narciso FV, Tufik S, Paiva T, Spence DW, BaHammam AS, et al. Sleep disorders as a cause of motor vehicle collisions. Int J Prev Med. 2013;4(3):246-57.

11. Young T, Blustein J, Finn L, Palta M. Sleep-disordered breathing and motor vehicle accidents in a populationbased sample of employed adults. Sleep. 1997;20(8):608-13, https://doi.org/10.1093/sleep/20.8.608. 
12. Sharma SK, Katoch VM, Mohan A, Kadhiravan T, Elavarasi A, Ragesh R, et al. Consensus \& evidence-based INOSA guidelines 2014 (first edition). Indian J Med Res. 2014;140(3):451-68.

13. Sharma SK, Kumpawat S, Banga A, Goel A. Prevalence and risk factors of obstructive sleep apnea syndrome in a population of Delhi, India. Chest. 2006;130(1):149-56, https:// doi.org/10.1378/chest.130.1.149.

14. Reddy EV, Kadhiravan T, Mishra HK, Sreenivas V, Handa KK, Sinha S, et al. Prevalence and risk factors of obstructive sleep apnea among middle-aged urban Indians: A community-based study. Sleep Med. 2009;10(8):913-8, https:// doi.org/10.1016/j.sleep.2008.08.011.

15. Transport Department. Application-cum-declaration as to the physical fitness [Internet]. Lucknow: The Department; 2014 [cited 2015 Mar 23]. Available from: http://upscdl. up.nic.in/Docs/forms1_1A.pdf.

16. Chung F, Yegneswaran B, Liao P, Chung SA, Vairavanathan S, Islam S, et al. STOP questionnaire: A tool to screen patients for obstructive sleep apnea. Anesthesiology. 2008;108(5): 812-21, https://doi.org/10.1097/ALN.0b013e31816d83e4.

17. World Health Organization. Appropriate body-mass index for Asian populations and its implications for policy and intervention strategies. Lancet. 2004;363(9403):157-63, https://doi.org/10.1016/S0140-6736(03)15268-3.

18. Misra A, Chowbey P, Makkar BM, Vikram NK, Wasir JS, Chadha D, et al. Consensus statement for diagnosis of obesity, abdominal obesity and the metabolic syndrome for Asian Indians and recommendations for physical activity, medical and surgical management. J Assoc Physicians India. 2009;57:163-70.

19. Young T, Skatrud J, Peppard PE. Risk factors for obstructive sleep apnea in adults. JAMA. 2004;291(16):2013-6, https://doi.org/10.1001/jama.291.16.2013.

20. Ralls FM, Grigg-Damberger M. Roles of gender, age, race/ ethnicity, and residential socioeconomics in obstructive sleep apnea syndromes. Curr Opin Pulm Med. 2012;18(6): 568-73, https://doi.org/10.1097/MCP.0b013e328358be05.
21. Pack AI. Advances in sleep-disordered breathing. Am J Respir Crit Care Med. 2006;173(1):7-15, https://doi.org/ 10.1164/rccm.200509-14780E.

22. Peppard PE, Young T, Palta M, Dempsey J, Skatrud J. Longitudinal study of moderate weight change and sleepdisordered breathing. JAMA. 2000;284(23):3015-21, https:// doi.org/10.1001/jama.284.23.3015.

23. Lam JCM, Sharma SK, Lam B. Obstructive sleep apnoea: Definitions, epidemiology \& natural history. Indian J Med Res. 2010;131:165-70.

24. Al Lawati NM, Patel SR, Ayas NT. Epidemiology, risk factors, and consequences of obstructive sleep apnea and short sleep duration. Prog Cardiovasc Dis. 2009;51(4):285-93, https://doi.org/10.1016/j.pcad.2008.08.001.

25. Netzer NC, Stoohs RA, Netzer CM, Clark K, Strohl KP. Using the Berlin Questionnaire to identify patients at risk for the sleep apnea syndrome. Ann Intern Med. 1999;131(7):485-91, https://doi.org/10.7326/0003-4819-1317-199910050-00002.

26. Chung F, Subramanyam R, Liao P, Sasaki E, Shapiro C, Sun Y. High STOP-Bang score indicates a high probability of obstructive sleep apnoea. Br J Anaesth. 2012;108(5): 768-75, https://doi.org/10.1093/bja/aes022.

27. Chung F, Yegneswaran B, Liao P, Chung SA, Vairavanathan S, Islam S, et al. Validation of the Berlin questionnaire and American Society of Anesthesiologists checklist as screening tools for obstructive sleep apnea in surgical patients. Anesthesiology. 2008;108(5):822-30, https://doi. org/10.1097/ALN.0b013e31816d91b5.

28. Farney RJ, Walker BS, Farney RM, Snow GL, Walker JM. The STOP-Bang equivalent model and prediction of severity of obstructive sleep apnea: Relation to polysomnographic measurements of the apnea/hypopnea index. J Clin Sleep Med. 2011;7(5):459-65.

29. Moser KA, Agrawal S, Davey Smith G, Ebrahim S. Socio-demographic inequalities in the prevalence, diagnosis and management of hypertension in India: Analysis of nationally-representative survey data. PLoS One. 
2014;9(1):e86043, https://doi.org/10.1371/journal.pone.00 86043.

30. Anchala R, Kannuri NK, Pant H, Khan H, Franco OH, di Angelantonio E, et al. Hypertension in India: A systematic review and meta-analysis of prevalence, awareness, and control of hypertension. J Hypertens. 2014;32(6):1170-7, https://doi.org/10.1097/HJH.0000000000000146.

31. Lakshman A, Manikath N, Rahim A, Anilakumari V. Prevalence and risk factors of hypertension among male occupational bus drivers in North Kerala, South India: A crosssectional study. ISRN Prev Med. 2014;2014:1-9, https://doi. org/10.1155/2014/318532.

32. Farag YMK, Mittal BV, Keithi-Reddy SR, Acharya VN, Almeida AF, Anil C, et al. Burden and predictors of hypertension in India: Results of SEEK (Screening and Early Evaluation of Kidney Disease) study. BMC Nephrol. 2014;15:42, https://doi.org/10.1186/1471-2369-15-42.

33. Kearney PM, Whelton M, Reynolds K, Muntner P, Whelton PK, He J. Global burden of hypertension: Analysis of worldwide data. Lancet. 2005;365(9455):217-23, https://doi. org/10.1016/S0140-6736(05)70151-3.

34. Das SK, Sanyal K, Basu A. Study of urban community survey in India: Growing trend of high prevalence of hypertension in a developing country. Int J Med Sci. 2005;2(2):70-8, https://doi.org/10.7150/ijms.2.70.

35. Ahmad K, Jafar TH. Prevalence and determinants of blood pressure screening in Pakistan. J Hypertens. 2005; 23(11):1979-84, https://doi.org/10.1097/01.hjh.0000187258. 86824.00.

36. Khoo SM, Tan WC, Ng TP, Ho CH. Risk factors associated with habitual snoring and sleep-disordered breathing in a multi-ethnic Asian population: A population-based study. Respir Med. 2004;98(6):557-66, https://doi.org/10.1016/ j.rmed.2003.11.017.
37. Ekici M, Ekici A, Keles H, Akin A, Karlidag A, Tunckol M, et al. Risk factors and correlates of snoring and observed apnea. Sleep Med. 2008;9(3):290-6, https://doi.org/10.1016/ j.sleep.2007.04.018.

38. Lavie L, Lavie P. Smoking interacts with sleep apnea to increase cardiovascular risk. Sleep Med. 2008;9(3):247-53, https://doi.org/10.1016/j.sleep.2007.03.018.

39. Sharwood LN, Elkington J, Stevenson M, Grunstein RR, Meuleners L, Ivers RQ, et al. Assessing sleepiness and sleep disorders in Australian long-distance commercial vehicle drivers: Selfreport versus an "at home" monitoring device. Sleep. 2012;35(4):469-75, https://doi.org/10.5665/ sleep.1726.

40. Alonderis A, Barbé F, Bonsignore M, Calverley P, de Backer W, Diefenbach K, et al. Medico-legal implications of sleep apnoea syndrome: Driving license regulations in Europe. Sleep Med. 2008;9(4):362-75, https://doi.org/10. 1016/j.sleep.2007.05.008.

41. Bonsignore MR, Randerath W, Riha R, Smyth D, Gratziou $\mathrm{C}$, Goncalves $\mathrm{M}$, et al. New rules on driver licensing for patients with obstructive sleep apnoea: EU Directive 2014/85/EU. Eur Respir J. 2016;47(1):39-41, https://doi. org/10.1183/13993003.01894-2015.

42. Strohl KP, Brown DB, Collop N, George C, Grunstein R, Han F, et al. An official American Thoracic Society clinical practice guideline. Sleep apnea, sleepiness, and driving risk in non-commercial drivers. An update of a 1994 statement. Am J Respir Crit Care Med. 2013;187:1259-66, https://doi. org/10.1164/rccm.201304-0726ST.

43. Ayas N, Skomro R, Blackman A, Curren K, Fitzpatrick M, Fleetham $\mathrm{J}$, et al. Obstructive sleep apnea and driving: A Canadian Thoracic Society and Canadian Sleep Society position paper. Can Respir J. 2014;21(2):114-23, https://doi. org/10.1155/2014/357327.

This work is available in Open Access model and licensed under a Creative Commons Attribution-NonCommercial 3.0 Poland License - http://creativecommons.org/ licenses/by-nc/3.0/pl/deed.en. 